\title{
Denying the Antecedent: A Common Fallacy?
}

\author{
MICHAEL B. BURKE Indiana University
}

Key Words: Fallacies; arguments; informal logic; logic.

\begin{abstract}
An argumentative passage that might appear to be an instance of denying the antecedent will generally admit of an alternative interpretation, one on which the conditional contained by the passage is a preface to the argument rather than a premise of it. On this interpretation, which generally is a more charitable one, the conditional plays a certain dialectical role and, in some cases, a rhetorical role as well. Assuming only a very weak principle of exigetical charity, I consider what it would take in a given case to justify accepting the less charitable interpretation. I then present evidence that those conditions are seldom met. Indeed, I was unable to find a single published argument that can justifiably be charged with denying the antecedent.
\end{abstract}

How often do real arguments, arguments actually given, commit the fallacies named, described, and classified in logic textbooks? Are these "common fallacies" truly common? No, probably they are not. That is the provocative claim of Maurice Finocchiaro.' If we interpret arguments sensitively and charitably, if we view them as enthymematic and/or non-deductive whenever it is reasonable to do so, then, Finocchiaro has argued, we will seldom be able to charge them with named fallacies. In response, Trudy Govier has disputed the adequacy of Finocchiaro's evidence. ' And Ralph Johnson has recorded his conviction, based on practical experience, that at least some of the named fallacies are indeed common. Johnson cites straw man, red herring, and ad hominem. (Hereafter "the named fallacies" will be simply "the fallacies.")

Note that there really are two questions: (1) How often are the fallacies committed?
(2) How often can the fallacies justifiably be charged? And note the advisability of considering the fallacies individually. It may be that some fallacies, such as straw man and begging the question, are often committed and can often be charged, that others, such as ad ignorantium, are rarely committed, and that still others, such as affirming the consequent, can seldom be charged even if they are frequently committed. (Perhaps charity will almost always require that an apparent example of affirming the consequent be taken as an inductive argument instead.) For pedagogical as well as theoretical purposes it would be desirable to have a sense, with respect to each fallacy, both of the frequency with which it occurs and of the frequency with which it can justifiably be charged ${ }^{4}$

In what follows I will discuss a single fallacy: that of denying the antecedent. I will offer evidence that this fallacy is less common, at least in print, than is often suggested. More importantly, I will identify an obstacle to charging this fallacy, an obstacle so serious that I know of no real argument that can justifiably be charged with denying the antecedent.

I want to stress that I will not be relying on some very strong principle of exigetical charity. Indeed, I will not rely on any principle of charity. I will need only a principle prohibiting the opposite of charity, one I will call (for want of a better name) the principle of fairness. Suppose we are choosing between two interpretations of a passage. And suppose that on interpretation $A$ the passage contains a fallacy, while on interpretation $B$ it does not. My principle of fairness requires only 
this: We should not prefer $A$ to $B$ unless the balance of textual, contextual, and other evidence favors $A$ over $B$. Principles of charity require that we presume, more or less strongly, the absence of fallacy. The principle of fairness requires only that we not presume the presence of fallacy. Now even for the principle of fairness, to which I anticipate no objection, it might prove challenging to provide a fully satisfactory theoretical justification. That is a task I will not here undertake. ${ }^{5}$

\section{I}

The fallacy of denying the antecedent is the fallacy committed by any (semantically invalid) deductive argument that has, when fully stated, the following form.

Premise: If $A$, then $B$

Premise: Not $A$

Conclusion: Not B

My bookshelves hold 78 logic textbooks and 3 theoretical works on fallacies. Of these, 44 mention the fallacy of denying the antecedent. And 17 say that the fallacy is common, tempting, or frequently confused with the valid forms modus ponens and modus tollens. In 5, all of them textbooks of formal logic, denying the antecedent and affirming the consequent are the only fallacies mentioned by name.

My 81 books offer many examples of denying the antecedent, of which the great majority are concocted. Below are some of their concoctions, followed by some of their examples of arguments actually given. ${ }^{6}$ When considering the concoctions, examples $1-3$, we will imagine that they are real utterances.

1. If capital punishment deterred murder, it would be justified. Since it doesn't, it isn't.

2. Broc Glover was considered sure to win if he had no bad luck in the early part of the race. But we have learned that he has had the bad luck to be involved in a crash right after the start, so we're expecting another driver to be the winner.

3. If the farmers will organize, they have a good chance of keeping the price supports. But who ever heard of farmers really getting together on anything? They are by occupation and conviction individualistic to the core.

4. Total pacifism might be a good principle if everyone were to follow it. But not everyone is [following it], so it isn't. (Gilbert Harman)

5. If antiabortionism required the perverting of natural reason and moral sensibilities by a system of superstitions, then the liberal could discredit it-but it doesn't, so he can't. (Roger Wertheimer)

6. "J. J.", I replied, "if it were any of your business, I would have invited you. It is not, and so I did not." (Paul Erdman)

I will come right to the point: These passages cannot fairly be charged with the fallacy of denying the antecedent, because there is no adequate reason to regard the conditionals they contain as premises. It is anything but unusual for a passage containing an argument to contain statements that are not parts of the argument. Each of our passages (except 6) contains an argument. But in no case is there adequate reason to consider the conditional a part of the argument. In each case it is at least as plausible to ascribe to the conditional some other role. In each case it is at least as plausible to take the argument to be an enthymematic instance of modus ponens (or of modus tollens, depending on the formulation of the unstated conditional).

Consider passage 1. The "since" enables us to identify as a premise the claim that capital punishment does not deter murder. And it enables us to identify the conclusion: Capital punishment is not justified. What it does not tell us is the role of the (stated) conditional. Is the conditional a part of the argument or a preface to it? Of course, the conclusion cannot validly be inferred solely from the premise flagged by "since." But that is no indication that 
the conditional is a second premise, since counting it as such would neither validate the inference nor even strengthen it. If there is some non-premisory role we might plausibly assign to the conditional, there is no apparent obstacle to doing so.

And indeed there is such a role: that of clarifying the nature of the arguer's objection to capital punishment, of making clear that the arguer opposes capital punishment only because the arguer believes it doesn't deter murder. This is a worthy role no matter what the circumstances, but it has special importance, rhetorically, if the arguer anticipates resistance to the argument. The arguer can use the conditional to "connect" with the audience. The conditional can serve to communicate, "Look, l'm not opposed to capital punishment on principle. I'm a pragmatist, not a moral absolutist. If I thought capital punishment deterred murder, I'd be for it."

But regardless of whether the conditional is meant to serve the rhetorical function of softening resistance, it serves (on the reading I suggest) the important dialectical function of indicating that the stated premise is, in the opinion of the arguer, crucial to the case for the conclusion: If the audience can cast doubt on the stated premise, the arguer will not simply substitute another argument for the same conclusion; the arguer believes that the conclusion stands or falls with the stated premise.

To sum up my comments on passage 1 , it is plausible to view the passage as consisting of a conditional statement followed by an enthymematic instance of modus ponens. (Findings reported in Section II suggest that real instances of modus ponens are almost always enthymematic.) Thus viewed, the argument contains one stated premise and this unstated premise: If capital punishment doesn't deter murder, then it isn't justified. The first sentence of the passage, the stated conditional, is not a part of the argument. It has, in addition to any rhetorical role, the dialectical role of revealing that the arguer accepts the conclusion only because the arguer accepts the stated premise.

Similar comments apply to all of our passages. In no case is there any textual indication that the (stated) conditional is a premise. In each case (except 6) it is plausible to ascribe to the conditional the dialectical role I have described. In most cases the conditional, thus understood, plays some other role as well. In passage 2 , the conditional serves to convey the dramatic significance of the argument: In all probability, the favorite has been eliminated. In passage 3 , the conditional serves, via its conversational implications, to identify the unstated premise and, thereby, the unstated conclusion. In passage 5 , the conditional may appear to have a polemical role: that of creating resentment toward the insulting "liberal." (If 5 seems especially weak, that's not because 5 truly is an instance of denying the antecedent. It's because of the doubtfulness of the unstated premise.) In passage 6, which I consider to be an explanation and not an argument, the conditional plays a role analogous to the dialectical role of the other conditionals: that of telling $\mathrm{J}$. J. that he was excluded only for the stated reason. (His exclusion was not overdetermined.) In addition, the conditional may be serving to assert the speaker's rectitude: Neither antipathy toward J. J., nor an ability to exploit his absence, nor any other unworthy motive would have resulted in the omission of an invitation, if the matter had been any of J. J.'s business.

Once stated it is obvious, I believe, that the conditionals are naturally and plausibly viewed in the way I suggest. Is there any good reason not to view them in this way? Is there any good reason to think that the conditionals are indeed parts of the arguments-and that the arguments are therefore formally fallacious? Well, if there is some contextual or circumstantial evidence in favor of such a view, if the arguers have admitted denying the antecedent, or if it has been determined through 
cleverly designed experiments that these arguers are highly susceptible to that fallacy, then the answer is yes. But no such evidence has been adduced. And none is apparent when one examines the sources? Absent such evidence, there is no apparent basis for charging the arguers with denying the antecedent. To do so would be unfairunless their arguments would be no better at all on the interpretation I have suggested. And for this condition to be met, it would not be enough, at least from a dialectical perspective, for the validating conditional to be less than certain, for it to be less than acceptable, or even for it to be downright implausible. It would have to be indisputably indefensible, that is, indisputably incapable of being made acceptable. After all, denying the antecedent is an indisputably indefensible form of argument. This stiff (but fair) requirement is satisfied in none of the examples we have considered-and in none of which I am aware. But for any example in which it is satisfied, I would allow that the charge of denying the antecedent is not unfair, even if, given the availability of an equally plausible interpretation, the charge is not differentially justified.

\section{II}

Are examples 1-6 in some way unrepresentative? Do we commonly encounter passages that are best viewed as instances of denying the antecedent? Is it likely that this fallacy is commonly committed, even in published writings, however hard it may be to justify charging the fallacy? In this section, I will offer some evidence in support of negative answers to these questions.

The fallacy of denying the antecedent is instantiable by passages of many different patterns. We will call any such pattern a " $B$ " pattern just in case any (argumentative) passage instantiating it will contain a textual feature indicating (even if not conclusively) that the conditional contained by the passage is a premise and that the passage, therefore, is an instance of denying the antecedent. Otherwise we will call it an " $A$ " pattern. (Thus an argumentative passage with an $A$ pattern might or might not be an instance of denying the antecedent. One with a $B$ pattern almost surely is.) Below are some patterns of each type.

A Patterns (relatively common)

(a) If $\mathrm{A}$, then B. Not A. So, not B.

(b) If $A$, then B. But not A. So, not B.

(c) If $\mathrm{A}$, then $\mathrm{B}$. Since not $\mathrm{A}$, not $\mathrm{B}$.

(d) If $A$, then $B$. But since not $A$, not $B$.

\section{B Patterns (uncommon)}

(e) Not A. If A, then B. So, not B.

(f) If $\mathrm{A}$, then $\mathrm{B}$. And not A. So, not B.

(g) Not A. Since B if A, not B.

(h) If $A$, then $B$. And since not A, not B.

(i) Not A. But if A, then B. So, not B.

(j) Not A. But since B if A, not B.

(k) Not $B$, since not $A$. And if $A$, then B.

(l) Not $B$, since $B$ if $A$. And not $A$.

(m) If $A$, then B. So not B, since not A.

Patterns (a)-(d) are $A$ patterns. In patterns (a) and (b), "so" immediately follows "not A." In (c) and (d), "since" immediately precedes "not A." These placements indicate that "not $A$ " is serving to support "not B." But none of the four patterns contains a textual indication that "If $A$, then $B$ " is playing the same role. None contains a textual obstacle to assigning to that conditional the dialectical and other roles that I have described.

Patterns (e)-(m) are $B$ patterns. In patterns (e), (g), (i), (j), (l), and (m), the positions of "so" and "since" indicate that "If $A$, then B" (or "B if A") is serving to support "not B." In (f), (h) and (k), the "and" indicates the same thing, although somewhat less strongly. (By contrast, the "but" in $A$ patterns (b) and (d) creates no presumption that the statements preceding it are premises. ${ }^{8}$ )

Now what is telling is that $A$ patterns are relatively common and their instantiations sound natural, while $B$ patterns are uncommon and their instantiations sound unnatural. (Return to Section I and hear 
what happens when passage 6 is changed from an (a) pattern to an (f) pattern by the addition of an "and." Hear what happens when passages 4 and 5 are changed to (f) patterns by substituting "and" for "but." Hear what happens when any of the six passages is recast into any $B$ pattern.)

In examining 81 books, as well as numerous articles on fallacies, 1 found 9 real passages said to be instances of denying the antecedent. (Textbook examples of fallacies are mostly concocted.) With one near exception, to be discussed below, none is an instance of any $B$ pattern. That is, none is an instance of any pattern in which indicator words make it reasonably clear that the passage is an instance of the fallacy of denying the antecedent. ${ }^{\text {? }}$

Assuming that my small (but laboriously collected) sample is representative, one question is this. If the fallacy of denying the antecedent truly is a common one, even among arguers sufficiently mature to have published writings, why is it that the fallacy generally is instantiated by passages exhibiting patterns ( $A$ patterns) that present no obstacle to a different interpretation? Why is it that the fallacy generally is not instantiated by passages exhibiting the many patterns ( $B$ patterns) that virtually preclude a different interpretation?

Perhaps it will be suggested that the answer lies simply in our preference, evident also with regard to the valid forms modus ponens and modus tollens, for placing the conditional premise first, the unconditional premise second, and the conclusion last. In reply, two points: First, even if there were such a preference, it wouldn't explain a dispreference for $B$ patterns (f) and (h), which $d o$ feature that order. Second, a survey of my sources did not confirm that the logician's preference when presenting argument forms is matched by the preferences of real-life arguers. I found 22 non-enthymematic, real examples of modus tollens. Only 8 exhibit the "preferred" order. I found I nonenthymematic, real example of modus ponens. (Yes, only 1) It does not exhibit the "preferred" order.

Now I am not suggesting that the fallacy of denying the antecedent is never or almost never committed. I do have the impression that a non-negligible percentage of students taking introductory logic are at least somewhat susceptible to this fallacy. For this reason (and others), I think it worthwhile for logic texts to distinguish modus ponens and modus tollens from the invalid forms denying the antecedent and affirming the consequent. But the evidence I have cited, limited though it is, does suggest that the fallacy of denying the antecedent is not common in published writings.

Rather more strongly the evidence suggests that published passages cannot often be charged with denying the antecedent. Passages exhibiting $A$ patterns are relatively common. But as we have seen, they readily admit of an alternative interpretation. It would be unfair to view them as formally fallacious unless there were some special reason for doing so. And in none of the cases known to me does either the context of the passage or any other salient circumstance supply such a reason. By contrast, passages exhibiting $B$ patterns can fairly be viewed as instances of denying the antecedent. But real passages exhibiting those patterns evidently are rare: I found none.

The closest thing I found to such a passage is one cited, as an example of denying the antecedent, by Rolf George, ${ }^{10}$ who identifies its source only as John 8:47. The speaker is Jesus:

He that is of God heareth God's words: ye therefore hear them not, because ye are not of God.

The position of "therefore" indicates that the first statement, "He that is of God heareth God's words," is a part of the argument (or explanation), not merely a preface to it. The passage has a pattern closely related to $B$ pattern $(\mathrm{m})$. 
Now I have not claimed that the charge of denying the antecedent is never justified. So I could cheerfully accept this as one case where it is. But there are three reasons not to. First, denying the antecedent is a sentential fallacy, whereas Jesus is guilty, if at all, of the predicate-logic analogue of that fallacy. Second, it is clear from the context (the preceding ten verses) that the passage is an explanation and not an argument. So again, the passage contains, at most, a logical error analogous to denying the antecedent. Third, and most important, the passage is probably a mistranslation. I checked four editions of the Bible and found four translations of the verse in question, all different from one another, and all different from the translation found by George. None contains the "therefore" or any other expression that identifies the generalization as a part of the explanans. None exhibits (an explanatory analogue of) a $B$ pattern. Here are the translations I found. ${ }^{13}$ (In each case, the verse is preceded by this question or its equivalent: "If I speak the truth, why do you not believe me?" Jesus then proceeds to answer his own question.)

He who belongs to God, listens to the words of God;

you do not listen to them, because you do not belong to God.

Whoever is of God hears every word God speaks.

The reason you do not hear is that you are not of God.

A child of God listens to the words of God; if you refuse to listen, $i$ is because you are not God's children.
He who has God for his father listens to the words of God.

You are not God's children, and that is why you do not listen.

To summarize: An argumentative passage exhibiting a $B$ pattern is a presumptive instance of denying the antecedent. But in Section II, I offered evidence that $B$ patterns are uncommon in published writings: I found not a single real instance. This, taken together with the results of Section I, suggests that published arguments can seldom be charged with denying the antecedent. Somewhat less strongly it suggests that published arguments seldom commit this fallacy.

In Section I, I argued, in effect, that it generally is unfair to regard a passage exhibiting one of the relatively common $A$ patterns as an instance of denying the antecedent. Such a passage can very plausibly be taken to contain an enthymematic instance of modus ponens (or modus tollens), unless there is some contextual or circumstantial obstacle to doing so. And I know of no case in which there is such an obstacle. The conditional contained by the passage can very plausibly be viewed as a preface to the argument, not as a part of the argument. Thus viewed, the conditional has, in addition to any rhetorical or other extra-dialectical purpose, the dialectical function of conceding that the acceptability of the stated premise is a necessary condition of the acceptability of the conclusion. $^{12}$

\section{Notes}

1 "Fallacies and the Evaluation of Reasoning," American Philosophical Quarterly 18, January 1981. In a later article, "Six Types of Fallaciousness," Argumentation 1, 1987, Finocchiaro offers his own list of six fallacies, but on the understanding that "we have a fallacy only within the framework of a given practitioner's conception of the argument he is commenting upon ... the fallaciousness of an argument is not seen as an objectively verifiable fact ..." (pp. 264-65).

2 "Four Reasons There are No Fallacies," Ch. 9, Problems in Argument Analysis and Evaluation, Dordrecht: Foris Publications, 1987, pp. 190-99. 
3 "The Blaze of Her Splendors: Suggestions About Revitalizing Fallacy Theory," Argumentation, Vol. 1, No. 3, 1987, p. 244.

4 There is no difficulty in understanding how we could have reason for believing the former to exceed the latter, providing the latter means something like "the frequency with which a given fallacy can justifiably be charged on the basis of information readily available."

5 For a survey of attempts to justify principles of charity, and for objections to strong principles of charity, see Trudy Govier, "A New Approach to Charity," Ch. 7, Problems in Argument Analysis and Evaluation, Dordrecht: Foris Publications, 1987.

6 Example I is my own concoction, one l've given several times to my students as an example of denying the antecedent. But essentially the same example is given in Jerry Cederblom and David W. Paulsen, Instructor's Manual to accompany Critical Reasoning, 3rd ed., Belmont, California: Wadsworth Publishing Company, 1991, p. 185. Example 2 is given in Brooke Noel Moore and Richard Parker, Critical Thinking, 3rd ed., Mountain View, California: Mayfield Publishing Co., 1992, p. 247. Example 3 is given in W. Ward Fearnside and William Holther, Fallacy: The Counterfeit of Argument, Englewood Cliffs: Prentice-Hall, Inc., 1959, p. 156. Example 5 is given in Lilly-Marlene Russow and Martin Curd, Principles of Reasoning, New York: St. Martin's Press, 1989,pp. 99-100. Examples 4 and 6 are given in Irving $\mathrm{M}$. Copi and Carl Cohen, Introduction to Logic, 8th ed., New York: Macmillan, 1990, p. 244 and p. 241. 1 consider example 6 to be an explanation and not an argument (even if some explanations are also arguments). But Copi and Cohen present it as an example of denying the antecedent.

7 Take passage 5, for example, which comes at the end of a paragraph. Here is as much of the context as seems pertinent to its interpretation. "Furthermore, even apart from the question whether moral principles are laws of reason, it cannot be true that the correct moral principles are limited to those principles that would apply in a Kingdom of Ends, where everyone acted morally and no one ever did anything wrong. In the real world not everyone acts morally and moral principles must allow for that. Total pacifism might be a good principle if everyone were to follow it. But not everyone is [following it], so it isn't." (Gilbert Harman, The Nature of Morality, New York: Oxford University Press, 1977, pp. 76-77.) Is the conditional statement a premise? Or is it a preface? I see nothing in the context that favors the former interpretation over the latter.

8 The conjunctions "and" and "but" differ pragmatically, if not semantically. When statements are conjoined with a "but" instead of an "and" often it is because the speaker takes the statements to have opposing or contrasting implications. Compare these passages: (1) "John was then in New York. And Sally was then in Toronto. So, Fred is lying." (2) "John was then in New York. But Sally was then in Toronto. So, Fred is lying." In (1), the use of "and" suggests that the statement preceding it is part of the basis for the conclusion. In (2), the use of "but" suggests the opposite.

9 Also significant is that very few even of the concocted examples exhibit $B$ patterns, no doubt because passages exhibiting those patterns lack the naturalness we prize when contriving examples.

10 "A Postscript on Fallacies," Journal of Philosophical Logic, Vol. 12, 1983, p. 323.

11 The sources, in corresponding order, are these: James Moffatt, trans. A New Translation of the Bible, New York: Harper \& Row, 1954, p. 126. Members of the Catholic Biblical Association of America, trans. The New American Bible, Saint Joseph Edition, New York: Catholic Book Publishing Co., 1970, p. 118. Alexander Jones, ed. The New Jerusalem Bible, Garden City, New York: Doubleday \& Co., Inc., p. 166. The Revised English Bible, New Rochelle, New York: Oxford University Press and Cambridge University Press, 1989, p. 89 of "The New Testament."

121 am not the first to note that what might appear to be an instance of denying the antecedent may instead be an enthymematic instance of modus ponens or modus tollens. Robert Fogelin and Timothy Duggan ("Fallacies," Argumentation, Vol. I, No. 3, 1987 , p. 258) suggest that in some apparent instances of the fallacy (they don't say which, or how many - they devote only a paragraph to the point), the stated conditional serves to imply, conversationally, its converse, which then serves as an unstated premise. Two brief comments: (1) This suggestion leaves unexplained why the arguer didn't simply state 
the converse instead. (So would any suggestion that the stated conditional is intended to bear the meaning of a biconditional.) (2) It is true that the use of the stated conditional may imply that the arguer believes the unstated converse of that conditional. But what makes the unstated converse an unstated premise, and what generally suffices to identify it as such, is the arguer's inferring of the conclusion from the stated, unconditional premise. When the stated conditional is not itself a premise, its primary purpose is to play the dialectical, rhetorical, and/or other roles that I have described.

Frans H. van Eemeren and Rob Grootendorst, while discussing the importance in argument analysis of pragmatic considerations, give a case in which a boy is told that he may not go to a movie if he does not tidy his room. The boy promptly tidies his room and then expects to be allowed to go to the movie. Van Eemeren and Grootendorst, also appealing to conversational implicature, argue that we need not take the boy to be denying the antecedent. We may take him to be relying on a premise conversationally implied by the stated conditional. (Argumentation, Communication, and Fallacies, Hillsdale, New Jersey: Lawrence Erlbaum Associates, Publishers, 1992, pp. 181-82.) In this sort of case, in which the reasoner is someone other than the stater of the conditional, I agree that the stated conditional may be seen as supplying, via conversational implicature, a premise.

I am grateful for the many comments and helpful suggestions of John Tilley, Kim Margason, and two referees for this journal, Jerry Cederblom and Rolf George.

MICHAEL B. BURKE

DEPARTMENT OF PHILOSOPHY

INDIANA UNIVERSITY

425 UNIVERSITY BOULEVARD

INDIANAPOLIS, IN 46202 